\title{
USOS DO PASSADO NOS ANIMES JAPONESES: A PRESENÇA DE IMAGENS MÍTICAS DAS DEUSAS DA DESTRUIÇÃO E DO MITO DOS IRMÃOS, EM NARUTO SHIPPUDEN
}

\author{
USES OF THE PAST IN JAPANESE ANIMES: THE PRESENCE OF \\ MYTHICAL IMAGES OF GODDESSES OF DESTRUCTION AND THE \\ MYTHS OF BROTHERS, IN NARUTO SHIPPUDEN
}

\author{
Rodolpho Alexandre Santos Melo Bastos ${ }^{1}$ \\ Daniel Lula Costa ${ }^{2}$
}

\begin{abstract}
RESUMO: Anime é um termo ocidental que se refere às animações japonesas. Algumas dessas animações possuem imagens alegóricas de mundos passados, mitológicos que são presentificados. Essas presenças (GUMBRECHT, 2010) imagéticas podem ser analisadas pela alegoria histórica (BENJAMIN, 1984) que atribui outra perspectiva de estudo da imagem, sendo possível identificar sintonias de mundos passados que são emanados no presente. Nesse sentido, as imagens transmitem temporalidades múltiplas e emanam o anacronismo (DIDI-HUBERMAN, 2011). Nosso objetivo é analisar as presenças transtemporais, com base nas teorias expostas, das imagens de Kaguya e de seus filhos Hagoromo e Hamura enquanto detentoras de mundos antigos que se presentificam através do anime, Naruto Shippuden, sendo identificáveis as imagens (e os traços) das deusas da destruição em Kaguya e do mito dos irmãos gêmeos em Hagoromo e Hamura.
\end{abstract}

PALAVRAS-CHAVE: presença; mitologia; Naruto; Kaguya.

ABSTRACT: Anime is a Western term that refers to Japanese animations. Some of these animations have allegorical images of mythological past worlds that are made present. These imagetic presences (GUMBRECHT, 2010) can be analyzed by the

\footnotetext{
*Este artigo se origina de pesquisa desenvolvida ao longo de 2019 na Universidade Federal de Santa Catarina sobre a relação entre as manifestações míticas antigas e medievais presentes no anime Naruto Shippuden.

${ }^{1}$ Doutor em História pelo Programa de Pós-graduação em História da Universidade Federal de Santa Catarina (UFSC), integrante do Núcleo Interdisciplinar de Estudos Medievais (Meridianum-UFSC), Grupo de Estudos entre o Feminino e o Masculino na Longa Duração (GEFEM-UFSC). E-mail: rodoxbastos@ gmail.com.

${ }^{2}$ Doutor em História Cultural pela Universidade Federal de Santa Catarina com período de doutorado sanduíche na Università di Bologna. Professor do colegiado de História da UNESPAR. Integrante do HCIR (História das Crenças e das Ideias Religiosas) da Universidade Estadual de Maringá e do Meridianum (Núcleo Interdisciplinar de Estudos Medievais) da Universidade Federal de Santa Catarina. E-mail: daniellcosta23@ yahoo.com.br.
} 
historical allegory (BENJAMIN, 1984) that attributes another perspective of study of the image, being possible to identify tunings of past worlds that are emanating in the present. In this sense, images transmit multiple temporalities and emanate anachronism (DIDI-HUBERMAN, 2011). Our objective is to analyze the transtemporal presences, based on the exposed theories, of the images of Kaguya and his sons Hagoromo and Hamura as owners of ancient worlds that present themselves through the anime, Naruto Shippuden, being identifiable the images (and the traits) of the goddesses of destruction in Kaguya and the twin brothers myth in Hagoromo and Hamura.

KEYWORDS: presence; mythology; Naruto; Kaguya.

\section{Introdução}

O termo 'anime' é uma denominação ocidental utilizada para se referir às animações japonesas, as quais podem ser divididas em inúmeros gêneros e ser caracterizadas por temáticas e narrativas. Além disso, de acordo com Neto (2013), o gênero do anime leva em consideração a faixa etária, o sexo e o gênero do público alvo, como estilo 'shõnen', para os garotos; 'shõjo', normalmente atribuído as garotas; 'seinen', aos rapazes; 'redisu' ou 'redicome' para as moças; 'josei' direcionado as mulheres; 'gekiga' (mas também o 'seinen') para o público adulto, dentre outros.

'Naruto Shippuden', fonte que utilizaremos para o desenvolvimento deste artigo, é caracterizado como estilo ‘shõnen', e é a versão audiovisual do seu 'mangá' (uma espécie de histórias em quadrinhos produzidas no Japão) homônimo, criado por Masashi Kishimoto e serializada na revista semanal 'weekly shõnenjump' desde 1999. O nome Naruto é o mesmo nome do protagonista - Uzumaki Naruto - da série e se divide em dois momentos: na sua fase criança e na sua fase adolescente, quando muda para o nome de 'Naruto Shippuden'.

O anime narra a trajetória de Naruto, que segue seu sonho de se tornar um ninja ('shinobi') da aldeia da folha ('Konoha'), com o objetivo final de vir a ser o líder de sua aldeia ('Hokage'). Além de Naruto, outros personagens se destacam, como Uchiha Sasuke e Haruno Sakura, seus companheiros de Equipe. Sua ambientação é próxima de uma organização política medieval, sendo denominada como feudal. Há, então, segundo a tradução, senhores 
feudais ('daimyõ') responsáveis para ditar as normas e regras políticas e econômicas das aldeias, os quais atuam em conjunto com os líderes das aldeias ('kages').

O conteúdo do anime é organizado por questões que entrelaçam religiões, mitologias, rituais e práticas de magia. Em seu universo, existe uma espécie de energia espiritual e vital em algumas pessoas, denominada de 'chakra' que, quando concentrada e treinada, pode ser manipulada para gerar 'jutsus' (técnicas de lutas), que se dividem em 'ninjutsus' (técnica), 'genjutsu' (ilusão), 'taijutsu' (combate corpo a corpo) entre outros. Na série, para conseguir realizar um 'ninjutsu' é necessário praticar gestos com as mãos, que representam animais e elementos da natureza, ao mesmo tempo em que se fala o nome do 'ninjutsu' a ser liberado, o que o aproxima de ritualísticas compostas por prática de magia ritualística. No caso, conforme Lévi-Strauss (1993), a magia depende de um processo ritualístico e de repetição para criar forte envolvimento entre o agente e a prática. Essa repetição torna frequente a presentificação do mito, no caso, o uso do chakra desde Kaguya. Em Naruto Shippuden, os 'jutsus' dependem de muito treino e de um processo contínuo para gerar o aperfeiçoamento necessário e promover a técnica de luta, muitas vezes desenvolvida pelo conhecimento do seu eu interior. As técnicas de mãos do 'ninjutsu' demonstram esse processo ritualístico que acessa o 'chakra' existente no interior do ser e, em alguns casos, o une com a energia do mundo ('senjutsu') e o promove por meio da conexão com o rito das mãos; somente o rito correto, a concentração e o desenvolvimento da técnica do chakra possibilitam um 'ninjutsu' eficaz. A conexão entre ser humano, natureza e energia é muito presente no anime estudado.

Dessa forma, somente por meio de treinos intensos e da concentração que essa energia pode ser liberada. Essa energia tem fortes relações etimológicas com conceitos da mitologia hindu e budista, também denominadas de 'chakra'. Na mitologia hindu a palavra 'chakra' provém do sânscrito e significa “roda”. Descrita nos 'Upanishades', principalmente no 'Mundaka', ela é caracterizada como energia vital que auxilia na abertura das rodas do 
corpo. Ela se articula de uma forma semelhante à do anime Naruto, já que a força do 'chakra' é difundida para sete pontos do corpo humano, no qual a energia vital flui, podendo se concentrar em partes específicas.

Neste contexto, o objetivo deste artigo é identificar as presenças transtemporais de elementos que estruturam as narrativas míticas do passado, transmitidas e movimentadas pelas imagens da personagem Kaguya Ōtsutsuki e seus dois filhos, Hagoromo Ōtsutsuki, conhecido 'Rikudou Senin' (Sábio dos 6 caminhos), e seu irmão gêmeo Hamura Ōtsutsuki. Tais personagens, que se configuram em nossos objetos de análises, presentificam imagens referentes às deusas da destruição, por meio de Kaguya e ao mito dos irmãos, através de seus filhos, uma vez que a existência do 'chakra' provém da personagem Kaguya e da sua trajetória de vida e de morte, sendo também a raiz de sua força. $O$ 'chakra' será melhor desenvolvido, trabalhado e manipulado por Hagoromo e Hamura. Para este artigo, iremos utilizar, como fonte, os episódios 458, 459, 460, 461, 462 e 463, que tem cerca de 23 minutos cada.

Dessa forma, é possível identificar a presença de elementos mitológicos em espaços midiáticos, como nas produções audiovisuais, o que permite novas formas de identificação contextual do antigo com o contemporâneo, de tradições culturais que saltam temporalmente, se intensificam e serpenteiam no imaginário de determinadas realidades sociais. Ou seja, 'Naruto Shippuden' é capaz de produzir ressonâncias de culturas e tradições do passado e suas bases mitológicas antigas que os toca, se fundindo com os elementos novos criados por meio do seu contexto temporal e espacial. Essas ressonâncias são transmitidas pela dinâmica das imagens, de sua presença e de seus sentidos conferidos pela alegoria de mundos passados presentes no anime.

A presença deste(s) passado(s) da (e na) imagem está de acordo com o que Hans Ulrich Gumbrecht (2010) afirmou ser o encontro de uma sensação tangível manifesta pela obra, que conecta o passado ao presente, praticado por uma 'cultura de presença'. Essa cultura de presença presentifica elementos de experiências temporais do passado, nos quais podemos acessá-los em sua materialidade, porque são palpáveis, capazes, inclusive, de tocar nossos corpos 
sensorialmente. Ela está em constante relação à uma cultura de sentido, ligada aos objetos culturais num processo que o autor chama de "interpretação" ou "campo hermenêutico".

Por outro lado, Aby Warburg (2015) denominou a presença desses elementos antigos de 'nachleben', ("pós-vida" ou "sobrevivência" de gestos, formas e expressões), quando se deteve, em seus estudos, sobre as presenças do paganismo nas imagens do Renascimento italiano. Ou seja, essas imagens do presente ressignificavam movimentos antigos, como foi o caso das obras de Botticelli e Dürer. Assim, as imagens têm a capacidade de manter relações com diferentes temporalidades, uma vez que possuem tempos históricos diferentes, de forma não linear e não separados.

Walter Benjamin (1984) também buscou a manifestação de tempos múltiplos na imagem, sobretudo, na tensão entre aquele que a vê e a imagem que o olha de volta, numa relação dialética promovida pela distância da imagem do ser humano que a contempla. Esta imagem passa a mover tempos do "Outrora" com o "Agora", entre o antigo e o novo, mito e novidade, tempos remotos e o presente, ao dinamizar tensões espaço/temporais que incomodam aquele que a vê. É nesse encontro de tempos heterogêneos entre o "Outrora" e o "Agora" em que se dá, o que Benjamin denominou como aura, que é o elemento de suspensão da imagem dialética.

Ainda segundo Benjamin (1984), ao manter em tensão o contexto em que a imagem é analisada e os seus mundos passados, é possível perceber os vestígios de suas temporalidades por meio da alegoria histórica. Isto permite uma desmontagem de seus elementos, para identificar em seus variados tempos, a relação deles com a presença do passado em consonância com o presente, numa espécie de lampejo ou relâmpago, formando, assim, algo mais complexo: a constelação de imagens.

Portanto, a imagem do passado é fixada como imagem que relampeja, na medida em que é reconhecida no presente por meio de seus fragmentos. Deste modo, alegoria histórica para Benjamin (1984), propõe compreender as relações entre as temporalidades de uma fonte histórica e seu espaço, que 
podem estar relacionados a elementos míticos antigos. Essa fonte é deslocada no tempo e acessada pelo alegorista, o qual deve compreender seus fragmentos, seus mundos passados e relacioná-los a seus sentidos.

Alinhado às ideias de Benjamin e Warburg, essa problematização do tempo da imagem também é uma preocupação do historiador da arte, Georges Didi-Huberman. Para o autor, existem inúmeras temporalidades cristalizadas na imagem, a qual não para de ser reconfigurada, mesmo as antigas, assim como o passado as reformula, por mais contemporânea que sejam. A imagem só se torna reconhecível por intermédio da memória, pois, estar diante de uma imagem é estar diante do tempo:

Diante de uma imagem, enfim, temos que reconhecer humildemente isto: que ela provavelmente nos sobreviverá, somos diante dela o elemento de passagem, e ela e, diante de nós, o elemento do futuro, o elemento da duração [dureé]. A imagem tem frequentemente mais memória e mais futuro que o ser [etant] que a olha (DIDI-HUBERMAN, 2015: p. 16).

Assim, as imagens possuem diferentes temporalidades e, mesmo contemporâneas, estão repletas de memórias e obsessões pelo passado (ou passados), se configurando numa imagem anacrônica. Segundo Didi-Huberman (2015, p. 15), propor o anacronismo é interrogar a plasticidade fundamental das imagens "[...] e, com ela, a mistura, tão difícil de analisar, dos diferencias tempos operando em cada imagem". Elementos como cores e traços permitem perceber significados que ultrapassam o tempo do artista e da obra, o que também pode ser aplicado ao anime 'Naruto Shippuden', se levarmos em consideração as roupas dos personagens, o movimento, a trilha sonora e a fotografia, por exemplo.

É a partir das considerações de Warburg, Benjamin, Gumbrecht e DidiHuberman, enquanto um referencial teórico e metodológico, que iremos desenvolver esse artigo, ao problematizar as imagens de Kaguya, Hagoromo e Hamura, personagens apresentadas no anime 'Naruto Shippuden'. Pois, tais personagens, por meio do anime, presentificam temas mitológicos de estruturas presentes em narrativas míticas do passado, como "a deusa da destruição" e o 
"mito dos irmãos". Além disso, entrelaçam culturas antigas e movimentam experiências temporais, ao demonstrar elementos do passado que são alegorizados e presentificados em suas imagens.

Algumas considerações sobre Kaguya, Hagoromo e Hamura, em 'Naruto Shippuden'

Para entender o aspecto destrutivo de Kaguya, enquanto deusa, e o mito dos irmãos referente a Hagoromo e Hamura, como temáticas que normalmente estão presentes em narrativas míticas do passado, é preciso salientar que estes personagens, são os fundadores de 'ethos' específico que norteia o universo 'shinobi' da série, 'Naruto Shippuden', no qual a história narrada sobre eles, acontece cerca de um milênio antes da trama principal que envolve o protagonista Naruto. Embora, tais personagens sejam constantemente mencionados na série em forma de 'flash back', eles reaparecem na trama atual, como é o caso de Kaguya, que se revelou a grande antagonista do anime, e Hagoromo, que auxilia o protagonista a derrotar sua mãe.

Desta forma, Kaguya, Hagoromo e Hamura operam, por meio de suas ações, combates e histórias de vida, como modelos fundadores de uma cosmogonia que norteia o universo ninja. Pois, foi através destas ações que originaram os principais conhecimentos, regras e princípios sobre a criação do mundo ninja e a manipulação de 'chakra'. Assim sendo, iremos nos concentrar, principalmente, nos episódios que narram sobre a relação destes três personagens para encontrarmos as possíveis conexões com o objetivo deste artigo.

Kaguya apareceu no planeta, a partir das estrelas, por volta de um milênio antes do tempo que se passa as aventuras de Naruto. Encontrada pela pequena nação de $S \bar{o}$, tornou-se a concubina do senhor desta nação, conhecido como Tenji, ficando grávida dele de gêmeos, posteriormente. Paralelamente, uma nação vizinha chamada $K o$ tenta usurpar parte das terras da nação de $S \bar{o}$. Esta situação cria uma tensão entre os dois países, obrigando Tenji a proibir seus súditos de atacarem a nação de Ko. Porém, Kaguya matou alguns homens 
desta nação ao se defender de uma tentativa de sequestro, levando Tenji a ordenar sua morte, como parte de um acordo para que a paz fosse mantida.

Figura 1: O surgimento de Kaguya

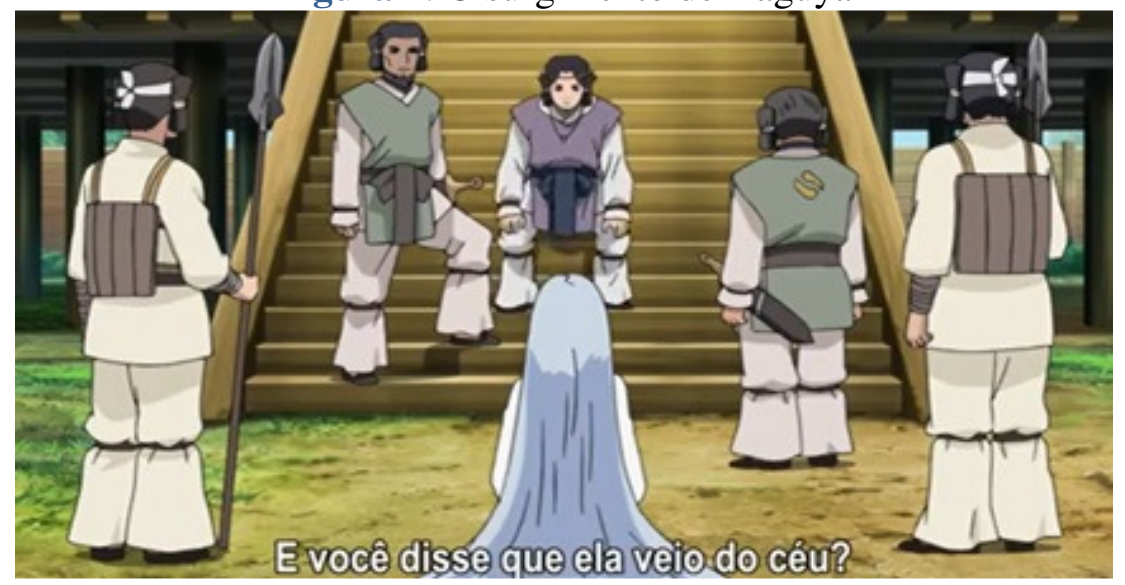

Fonte: KISHIMOTO, Massami. Naruto Shippuden. Japão: Pierrot, 2007-2017 (23 minutos).

Por esta razão, Kaguya sai em busca dos poderes contidos no fruto proibido da Árvore Divina 'Shinju'. O próprio acesso a esta árvore e os lugares próximos a ela, também eram proibidos, porque além de ser considerada sagrada, era perigosa. Kaguya, além de querer assegurar sua vida, também pretendia ter poder suficiente para pôr fim a todos os conflitos da humanidade.

Com seu novo poder, Kaguya se salvou e conseguiu findar as guerras existentes, através de um 'Genjutusu' chamado 'Mugen Tsukuyomi’ ("Reino do pesadelo infinito"), que aprisionava suas vítimas em uma ilusão de um mundo de paz. No entanto, Kaguya libertou algumas pessoas (pois, não queria viver sozinha), apagando suas memórias, permitindo somente a lembrança que foi a responsável pelo fim das guerras. Após dar à luz seus dois filhos gêmeos e estar estabelecida entre os humanos, Kaguya punia seus opositores com o 'Mugen Tsukuyomi', o que a transformou em uma tirana. Esta situação alterou a imagem de uma Deusa benevolente, para um demônio, o que motivou seus filhos a lutarem contra ela. 
Figura 2: Mugen Tsukuyomi

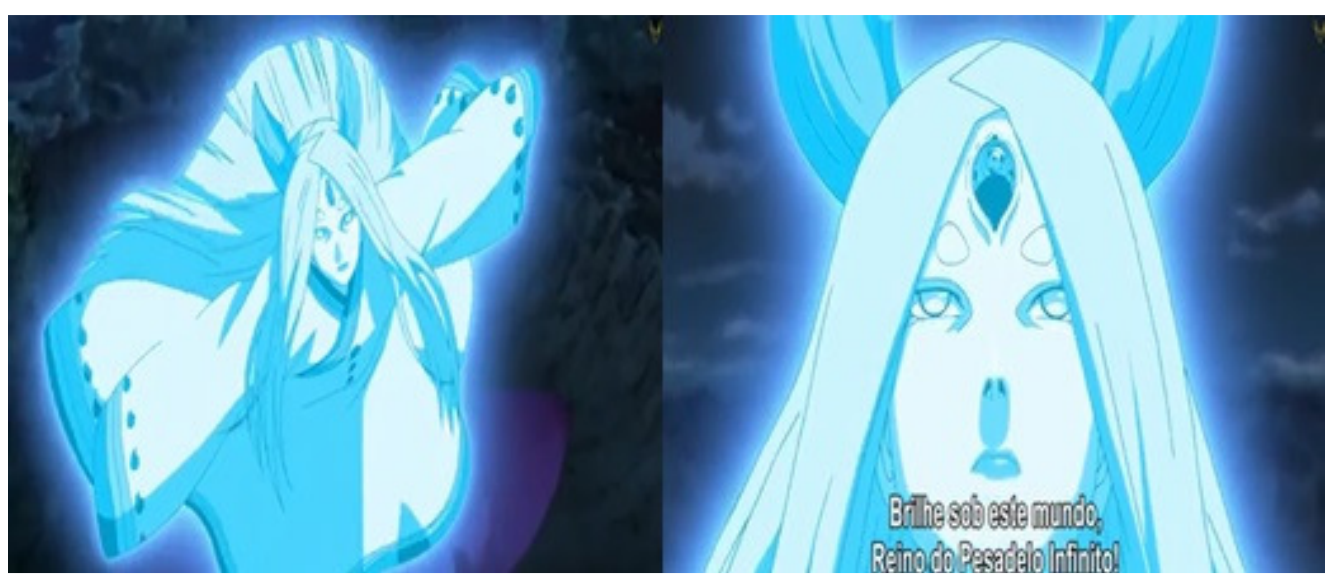

Fonte: KISHIMOTO, Massami. Naruto Shippuden. Japão: Pierrot, 2007-2017 (23 minutos)

Durante a batalha, Hamura e Hagoromo separaram e absorveram o 'chakra' de sua mãe, aprisionando-a no centro de uma esfera composta por pedaços do solo e de rochas, que se transformou na Lua. Hamura, filho mais novo de Kaguya, parte para a Lua para proteger a prisão de sua mãe. Hagoromo, por sua vez, permaneceu na terra para difundir sua religião do 'Ninshū'.

Esta breve síntese, nos possibilita encontrar alguns dos mesmos elementos míticos que estão presentes em narrativas míticas da antiguidade. A própria origem de Kaguya pode ser entendida como aquilo que Mircea Eliade (1972) denomina como "Ente Sobrenatural”, pois, graça a suas façanhas, um novo cosmo é criado. Ademais, Kaguya chega a ser considerada, no anime, a progenitora do 'chakra', além de possuir uma origem supralunar, ao vir dos céus.

\section{O mito dos irmãos e o aspecto destrutivo de Kaguya}

O elemento dos irmãos predestinados é fruto de práticas religiosas, mitológicas e ritualísticas da cultura humana. Sua existência se desenvolve perante a sensação de estar em um mundo culturalmente organizado, onde as pessoas nascem e se desenvolvem em conexão com a natureza e com a ideia da 
predestinação, ou seja, de existir um modelo a se seguir, uma profecia ou prática mitológica que emane uma determinada conduta. Os irmãos, normalmente, se desenvolvem em polos opostos, sendo destinados a confluir os aspectos caóticos do cosmos a uma determinada destruição ou ordenação, dependendo do papel a ser desempenhado.

O mito dos irmãos é visualizado na narrativa de Rômulo e Remo, Caim e Abel, Castor e Pollux, Thanatos e Hipnos, Osíris e Seth, Zeus e Hades, dentre outros. Visualizaremos em alguns deles a relação entre o mito dos irmãos e o aspecto destrutivo de Kaguya para analisar a presentificação de mundos passados (GUMBRECHT, 2010) evocados da imagem das deusas e das suas relações mitológicas encontradas em alguns mitos. É na imagem presente no anime que os tempos se chocam sendo possível visualizar esses cruzamentos temporais presentes na fonte (DIDI-HUBERMAN, 2011).

Para Chevalier e Gheerbrandt (1986), quando gêmeos, os irmãos são intervenções das dualidades presentes no ser como o espiritual e o material, o bem e o mal, e aquelas verificadas na natureza o dia e a noite, o sol e a lua, os aspectos terrestres e celestes. No caso, mesmo nas divindades irmãs que não carregam a características de serem gêmeas, é possível verificar esses aspectos. Essa bipolaridade pode ser sentida nos filhos gêmeos de Kaguya: Hagoromo e Hamura.

A narrativa mitológica do anime 'Naruto Shippuden' é constituída perante atos cósmicos vinculados ao eterno retorno (ELIADE, 1972). Kaguya é a progenitora do chakra, elemento que vincula energias poderosas à existência vivente. Essa energia existe a partir dela e é transmitida para suas gerações. A partir disso, os seus filhos são criados e ensinados a utilizar o 'chakra'. A narrativa atribui às almas dos irmãos uma existência eterna que pode retornar $\mathrm{e}$ agir em outros corpos no decorrer do tempo.

Após a morte de Hagoromo e Hamura, outros irmãos nascem predestinados a seguir os seus passos, dentre os quais está a vivência benevolente, a convivência, a disputa entre si, a busca pelo conhecimento da força do 'chakra' e o atrito entre os dois polos. De acordo com o anime, esses 
irmãos são reencarnações dos filhos de Hagoromo. As existências vinculadas pelos laços da eternidade são manifestadas em corpos que não precisam, necessariamente, terem nascido de uma mesma mãe, mas manifestam uma necessidade de harmonia, disputa e caos, ou seja, o rito primordial do mito.

No caso dos filhos de Kaguya, há a característica de serem gêmeos bivitelinos, ou seja, não são idênticos. O componente importante é terem nascido da mesma mãe, aquela que chega à Terra por meio do céu, sendo ambos os primeiros seres a nascerem com chakra. Pela linhagem, nascem os dois filhos do Sábio dos Seis Caminhos (Hagoromo), Ashura e Indra. Após os conflitos entre os irmãos, as suas energias passam a reencarnar na Terra, gerando outros descendentes diretos do chakra. Sendo assim, esses chakras renascem em Hashirama Senju (Ashura) e Uchiha Madara (Indra) e, após a morte deles, em Naruto Uzumaki (Ashura) e Uchiha Sasuke (Indra).

Kaguya é o polo central de toda essa regularidade de encarnações do 'chakra'. Seu poder e energia advém de outra existência que não a terráquea, o qual permite que ela manipule a energia emanada do fruto da Árvore Divina, liberando o 'chakra' e suas energias vitais. Essa Árvore possui raízes em que são colocados corpos de pessoas para que a planta se revigore e permaneça viva ao sugar os 'chakras' dos seres vivos. A simbologia da Árvore Divina é muito similar à da Árvore do Conhecimento presente no Antigo Testamento (Gn, 3: 89). O fruto oferecido pela árvore da tradição judaico-cristã remete ao sacrifício de Adão e Eva para saborearem o conhecimento, sendo então expulsos do Paraíso. De acordo com Eliade (1992), a árvore possui uma simbologia de vida, do cosmo, da imortalidade e carrega toda a energia vital, ligando o céu e a terra, como se fosse um polo conectivo entre os deuses e o ser humano. Comer de seu fruto é obter a energia vital da ligação proveniente do divino.

Conforme demonstrado, Kaguya come do fruto enquanto está grávida e promove a seus filhos a mesma energia. É notável que o papel da 'Ōtsutsuki' se altera nesse momento da narrativa, quando ela decide optar por uma investida mais ofensiva contra os terráqueos ao invés de se concentrar no objetivo de promover a paz. Nesse contexto que ela cria seus dois filhos. 
A narrativa do anime informa, no episódio 460, que o papel de Kaguya, ao aparecer na Terra, é de proteger a Árvore Divina mas, posteriormente, no episódio 461 ela é descrita como aquela que comeu do fruto para defender seus dois filhos, que estavam em seu ventre. Os filhos nascem e crescem, criados em uma cultura que se desenvolve perante o Ritual da Árvore Divina, em que seres humanos são selecionados por Kaguya para irem a Árvore e se sacrificar pelo seu poder, que consome a sua energia e os enclausura em sua raiz. A Árvore, então, é um elemento que dá poder e conhecimento, mas que promove, também, a destruição da natureza. $\mathrm{O}$ destino dos irmãos é revelado pelo aparecimento do sapo Gamamaru, que demonstra o papel desempenhado pela Árvore Divina e da existência de uma profecia revelada por meio de um sonho. Essa profecia afirmava que os irmãos deveriam enfrentar a mãe. Gamamaru ensina a Hagoromo o Poder Sábio que é sentido e usado pelos sapos, ou seja, um poder que provém da natureza e que pode ser um elemento para vencer Kaguya.

Figura 3: Hogoromo e Hamura.

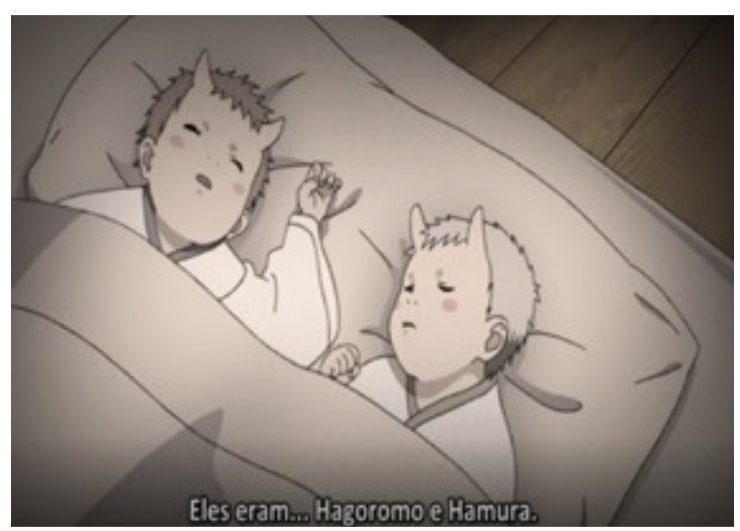

Fonte: KISHIMOTO, Massami. Naruto Shippuden. Japão: Pierrot, 2007-2017 (23 minutos)

Vemos aqui semelhanças comuns ao mito judaico-cristão presente no 'Gênesis', possíveis de serem visualizadas na personagem de Eva e seus dois filhos Caim e Abel. Eva e Kaguya podem ser relacionadas por meio de algumas características enquanto seres femininos que comem do fruto e que tem consequências após adquirir o conhecimento proibido. Eva sofre por ser 
marcada pelo pecado, ou seja, por ter ingerido o fruto da árvore do conhecimento, tendo, então, desobedecido as ordens divinas, assim como Adão. Ao comer do fruto, Kaguya também tem consequências, dentre as quais está a sua vinculação a um ser a ser temido e demonizado. Seus filhos Hagoromo e Hamura (Figura 3), no entanto, não são tão semelhantes a Caim e Abel, porém, carregam alguns elementos marcantes que serão continuados por Ashura e Indra.

No mito judaico-cristão, Caim e Abel são filhos de Adão e Eva (Gn. 4, 1-16). Apesar de não ser claro se são irmãos gêmeos, é notável que Caim nasce antes de Abel, sendo o mais velho. A relação interessante é o papel desempenhado por cada um deles. Ao nascerem, após a expulsão do Paraíso Terrestre, eles desenvolvem práticas diferentes, sendo Caim relacionado ao cultivo do solo e Abel a pastorear as ovelhas. Importante salientar que essas práticas são desenvolvidas após a ingestão do fruto do conhecimento por Adão e Eva. Essa distinção promove a identidade de cada um deles em relação a Iahweh, que se desaponta com Caim quando ele e Abel oferecem presentes a ele, preferindo aquele entregue por Abel. É nesse envolvimento de disputa que Caim decide matar o próprio irmão.

As semelhanças com Hagoromo e Hamura são manifestas pelas diferenças de práticas que envolvem cada um dos irmãos e pela sua descendência direta estar relacionada a ingestão do fruto da Árvore Divina. Hagoromo consegue controlar o 'chakra' e desenvolver o Rinnegan ${ }^{3}$ e o Sharingan ${ }^{4}$, já Hamura o Byakugan ${ }^{5}$ e Tenseigan ${ }^{6}$. Há diferença na prática e na

\footnotetext{
${ }^{3}$ Rinnegan significa "olho da transmigração". É uma técnica ocular (dōjutsu) que concede habilidades específicas ao portador, deixando o olho em tom roxeado com várias ondulações concêntricas. Ele é uma técnica passada pela herança sanguínea, geneticamente (Kekkei Genkai), porém, ao ser isolado em um órgão do corpo humano, é possível transmití-lo fisicamente a outra pessoa.

${ }^{4}$ Sharingan significa "olho copiador giratório". É uma técnica ocular (Dōjutsu) que aparece em membros do clã Uchiha e lhes concede habilidades específicas. É caracterizado pelo tom avermelhado do olho, tendo vários formatos e evoluções.

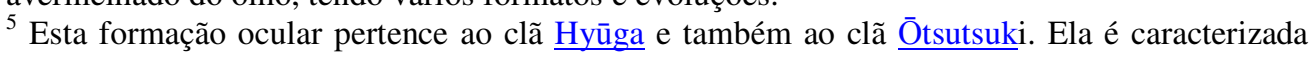
pelo tom acinzentado e pelas habilidades que concede ao portador. Byakugan significa "olho branco".

${ }^{6}$ Significa "olho da reencarnação", considerado uma poderosa técnica ocular utilizada pelo clã Ōtsutsuki.
} 
natureza de cada um deles. Essa relação de opostos, de diferenças, é sentida em mitologias variadas que relacionam a figura dos gêmeos aos opostos "A la dualidade de los gemelos míticos se aplica el curso ascendente (evolución) y descendente (involución) del sol”"7 (CHEVALIER; GHEERBHANT, 1986: p. 527). A figura e simbologia do sol e da lua também se manifestam nos dois irmãos criados por Kaguya.

A oposição divina também é encontrada na relação entre Iahweh, Caim e Abel e naquela entre Kaguya, Hagoromo e Hamura. Assim como Iahweh, é Kaguya que promove o conflito entre irmãos, quando prevê que eles estavam tramando enfrentá-la. Ela, então, passa a controlar Hamura e possibilita o conflito entre ele e seu irmão com a intenção de comprovar se o amor de Hagoromo é realmente verdadeiro, ou seja, se ele seria ou não capaz de matar o irmão. Hagoromo defere um golpe mortal em Hamura, mas consegue curá-lo por meio de uma técnica em pergaminho entregue a ele por Gamamaru. Mesmo sendo curado, um irmão mata o outro por um pequeno momento. A partir disso, Hogoromo desperta o Rinnegam e o Mangekyo Sharingan, olhos que carregam um poder grandioso.

Nesse contexto, podemos salientar o envolvimento existente entre o despertar e o dormir e sonhar. Para despertar o Mangekyo Sharingan e o Rinnegam é necessário que Hagoromo mate seu irmão Hamura, mesmo que ele não morra plenamente, a morte é sentida pelo ato de um golpe fatal. A relação de ambos é muito similar aos deuses gêmeos presentes na mitologia grega, Thanatos e Hipnos. Os deuses da morte e do sono respectivamente são imagens da relação de culturas, nas quais o sono era associado à morte e ao morrer se despertava. De acordo com Eliade, essa é uma situação de envolvimento soteriológico relacionado ao mito, "Desde que Hipnos é irmão de Tanatos, compreende-se porque, na Grécia como na Índia e no gnosticismo, a ação do 'despertar' tenha uma significação 'soteriológica”" (ELIADE, 1972: p. 91). No caso de Hagomoro, o despertar do poder de seus olhos é resultado do ato de

\footnotetext{
7 “À dualidade dos gêmeos míticos se aplica o curso ascendente (evolução) e descendente (involução) do sol” (tradução nossa).
} 
matar seu próprio irmão. Se ativa a visão quando se aniquila uma vida, assim como se desperta da morte para a salvação. Ao conhecer a morte se desperta para a vida e outro conhecimento é adquirido, o ato de sentir a impermanência do ser.

Outra conexão mitológica possível é a narrativa de Rômulo e Remo enquanto fundação da cidade de $\operatorname{Roma}^{8}$. Os dois irmãos gêmeos nascem por meio de um ato de violência sexual entre o deus da guerra, Marte, e Réia Sílvia. Os recém-nascidos são postos no rio Tibre a mando do avô (BUSTAMANTE, 2001). Em um determinado momento, uma loba os encontra e os amamenta, dando vitalidade aos irmãos. O animal seria um sinal da divindade ao revelar a importância de Rômulo e Remo para Roma. A partir disso, os irmãos crescem e determinam regiões de fronteira a partir de presságios revelados, o que acontece com Rômulo, fato que enraivece Remo que invade o local e acaba sendo morto pelo irmão (BUSTAMANTE, 2001).

Nesse mito, podemos relacionar a aparição de um animal como sinal da importância dos irmãos para a sua predestinação, como foi o caso da loba. Em 'Naruto Shippuden', há o envolvimento de um animal simbólico para o Japão, o sapo. Gamamuru é o sapo que revela a profecia aos irmãos e ensina a técnica do Poder Sábio para Hagoromo. A loba, na mitologia romana, é uma alegoria do mundo dos mortos e do renascimento assim como da ordem primordial preexistente ao homem (BUSTAMANTE, 2001), concedendo aos irmãos um papel ligado a violência e ao caos. Já os irmãos Hagoromo e Hamura são apresentados ao sapo, um animal de sabedoria, que lhes concede um determinado saber, que dá início à prova iniciática ao fomentar a ideia de serem eles os escolhidos para que a sociedade humana e a natureza prevaleçam. O conflito entre irmãos e a morte de um deles também é um elemento mítico importante para o despertar de uma geração, de um elemento mágico ou de uma situação política, o que acontece em ambos os casos.

\footnotetext{
${ }^{8}$ De acordo com Bustamante (2001), as narrativas analisadas em seu estudo sobre a construção da identidade romana a partir dos escritos e ritos sobre a fundação de Roma são: Tito Lívio e sua obra História de Roma, Dionísio de Halicarnasso e Antiguidades Romanas, Plutarco e Vida de Rômulo.
} 
Sendo assim, Hamura e Hagoromo batalham contra Kaguya durante muito tempo, até que conseguem vencê-la selando-a na Lua, fato que enfraquece o Juubi (Árvore Divina que ganha vida após a batalha dos irmãos). Esse selamento é feito por meio de Hagoromo com o símbolo do Sol presente na palma da mão e Hamura com o símbolo da Lua na palma de sua mão. Quando ambos tocam o corpo de Kaguya eles liberam o 'Chibaku Tensei' (Devastação Planetária) e a selam em uma rocha grandiosa que vem a se tornar a Lua. Hagoromo divide o Juubi em nove almas animalescas e as guarda até sua morte, quando os lança para várias partes do mundo.

Esses elementos carregam características importantes da Cabala judaica, desenvolvida em sua fase clássica, a partir do século XIII (DAL PRA, 1990: p. 246). A Cabala promove a ideia da 'Sefirot', ou seja, da árvore da vida e seus dez números primordiais (DAL PRA, 1990: p. 252). Nela estão presentes dez passos para se chegar ao divino, o qual se manifesta no último passo enfrentado por aquele que lê e estuda a Cabala. Esse aspecto é notável na presença da Árvore Divina em 'Naruto Shippuden', além dela, as nove almas da Juubi e o acesso ao divino promovido pela união dos dez passos. Sendo assim, para reviver Kaguya é necessário unir as nove almas da Juubi para despertar a árvore divina e, assim, preparar os elementos para ressuscitar Kaguya.

A relação entre os filhos de Kaguya não é complicada e ofensiva, na realidade, a narrativa demonstra uma relação de compreensão e de ajuda mútua. Esse aspecto é interessante, já que ambos estão predestinados a combater a própria mãe. É na cooperação que eles conseguem ter sucesso e vencê-la. O selamento se desenvolve a partir da união de dois elementos opostos que controlam a destruição e a ordenação de mundo. No anime, Kaguya desenvolve a alegoria da deusa da destruição, usando das energias da Terra para sobreviver e criar seus filhos, porém, a ordenação se desenvolve perante o seu selamento e a criação dos poderes dos polos Sol e Lua, dia e noite. Dessa forma, a humanidade sempre sentiu a tensão dos polos que se desenvolveram na reencarnação dos filhos de Hagoromo, Ashura e Indra, os quais foram constantemente tentados por uma parte de Kaguya que sobrevivera na Terra. Na 
Figura 4 é possível visualizar a tensão dos opostos enquanto ordenação e canalização da destruição.

Figura 4: Chibaku Tensei: selamento

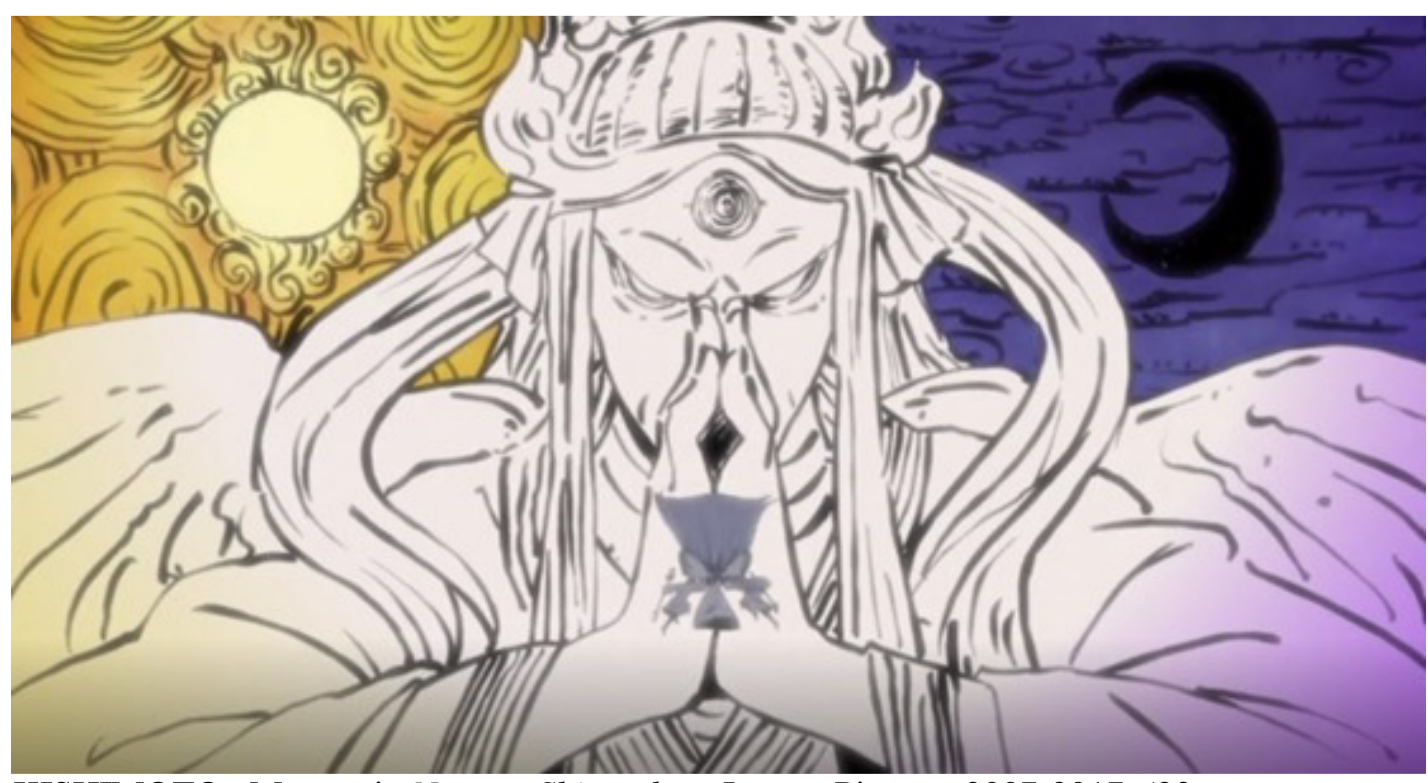

Fonte: KISHIMOTO, Massami. Naruto Shippuden. Japão: Pierrot, 2007-2017 (23 minutos)

$\mathrm{Na}$ Figura 4, pode-se visualizar, no lado esquerdo da imagem, a figura do Sol, claro e amarelado; do outro lado evidencia-se a presença da cor arroxeada que dá aspectos da noite para simbolizar a presença da Lua. No centro da imagem, o 'ninjutsu Chibaku Tensei' enquanto figura grandiosa que se manifesta a partir do contato das mãos dos irmãos em Kaguya, ato demonstrado na imagem menor que está nas palmas das mãos da figura do 'ninjutsu'. Ali, vemos os irmãos liberando o 'ninjutsu' juntos e selando a alma da mãe com as rochas que comporão a Lua. Há, então, o contato de dois polos, o claro e o escuro, que estimulam a recriação de um mundo novo, sem a postura tirânica desempenhada por Kaguya nesse ponto da narrativa. É uma narrativa mitológica baseada nas ideias escatológicas de um mundo que se destrói e outro que recomeça. Esses polos, que a mitologia elenca enquanto movimentos da natureza em aspectos divergentes, mas não desassociados, também pode ser relacionado ao 'Yin e Yang' do taoísmo (figura 5). O 'yin' seria o princípio da 
Lua e o 'yang' o do Sol, “yang e o yin estão presentes em todas as coisas. Eles não podem ser separados; tampouco podem ser julgados moralmente como bom ou mau. Funcionando juntos, em constante interação, predomina, ora um, ora outro" (CAMPBELL, 1994: p. 30).

Figura 5: Yin e Yang

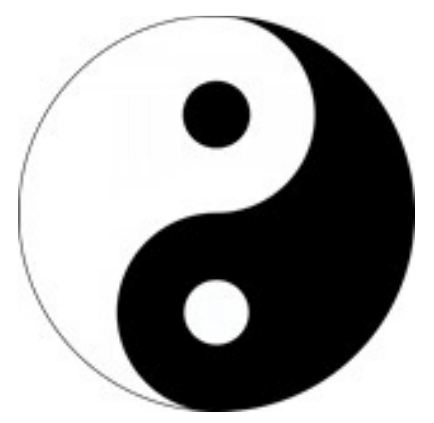

Fonte: Yin $\quad$ e $\quad$ Yang. Disponível em: https://www.astrocentro.com.br/blog/esoterismo/yin-yang-significado/. Acesso em: $10 / 01 / 20$.

Kaguya emana a presença de deusas antigas em si e as presentifica sob vários aspectos. Suas características enquanto aquela que vem do céu e progenitora do 'chakra' também a direcionam sob o aspecto do Céu, da presença do elemento ar e de sua postura como ser divino que passa a fazer parte da terra ao lado da Árvore Divina. De acordo com Eliade (2008), o Céu tem um aspecto de transcendência considerado além da humanidade e local de convivência dos deuses e deusas, “O 'alto' é uma dimensão inacessível ao homem como tal; pertence por direito às forças e aos seres sobre-humanos; o que se eleva subindo cerimoniosamente os degraus de um santuário ou a escada ritual que conduz ao Céu deixa então de ser um homem" (ELIADE, 2008: p. 40).

Kaguya vem do alto, do Céu, se instaura na Terra como aquela que detém um saber diferenciado, pois, passa sempre seu tempo olhando para as estrelas, parecendo esperar alguém ou alguma coisa. Posteriormente, ela sente os aspectos violentos do ser humano e passa a tentar modular uma conduta 
diferenciada, ligada ao sacrifício à Árvore Divina. Com a ameaça dos irmãos, Kaguya sente os aspectos de seu modelo de mundo abalados, principalmente quando é derrotada e selada. É possível visualizar essa etapa enquanto o fenômeno de destruição da existência, tanto ao sugar as energias da humanidade e da natureza quanto no momento em que se sente ameaçada pela sua linhagem. Kaguya demonstra ser dotada de características mitológicas variadas: pacificadora e ordenadora; criadora por meio da destruição; destruição e renascimento.

Dessa forma, Kaguya enquanto imagem das deusas da destruição, não pode ser compreendida sem uni-la ao aspecto da Juubi, a Árvore Divina. Na narrativa do anime, é afirmado que a Juubi é parte de Kaguya, ou seja, que ao despertar a Juubi Kaguya tem o objetivo de vencer seus filhos e reinar novamente. A Juubi é um ser híbrido dotado de características vegetais (árvore, madeira, folhas) e animalescas (patas, boca, olhos). Em diversas mitologias é possível verificar a associação da destruição, do mito escatológico, relacionado a vertentes animalescas e humanoides. No caso da mitologia egípcia, é Sekhmet (Figura 6) que tem o aspecto da guerra e do conflito. Uma deusa representada pelo corpo humanoide com o rosto de leoa.

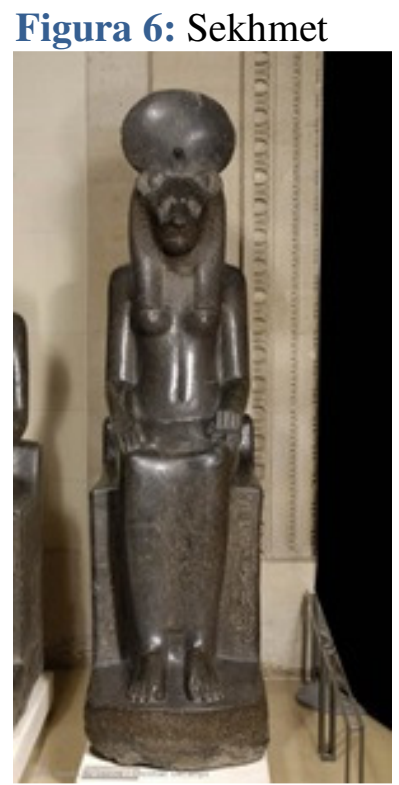

Fonte: Sekhmet. Disponível em: https://www.louvre.fr/en/oeuvre-notices/statuegoddess-sekhmet. Acesso em:10/01/20 
A religião hindu também remete a características possíveis de serem visualizadas no aspecto destrutivo de Kaguya. Primeiramente, quando Kaguya surge ela se demonstra benevolente e associada às virtudes da paz e do amor, porém, após o conflito entre as nações de $S \bar{o}$ e $K o$, Kaguya é traída por Tenji e demonstra sua natureza de conflito e guerra. Na mitologia hindu os aspectos das esposas de Shiva carregam essa natureza mais polarizada, entre a ordenação, como é o caso de Parvati, e a destruição, como é o caso de Durga em sua forma de Kali (BANSAL, 2008). Quando Durga se transforma em Kali, ela manifesta seu caráter conflituoso, de guerreira. Após ter concluído sua disputa e sido vitoriosa, Kali começa a dançar, mas a sua dança constante abala a Terra e mata inúmeras pessoas (BANSAL, 2008). Esses aspectos de criação, ordenação e destruição são comuns aos mitos. Na personagem de Kaguya é possível visualizar esse conflito entre características divinas.

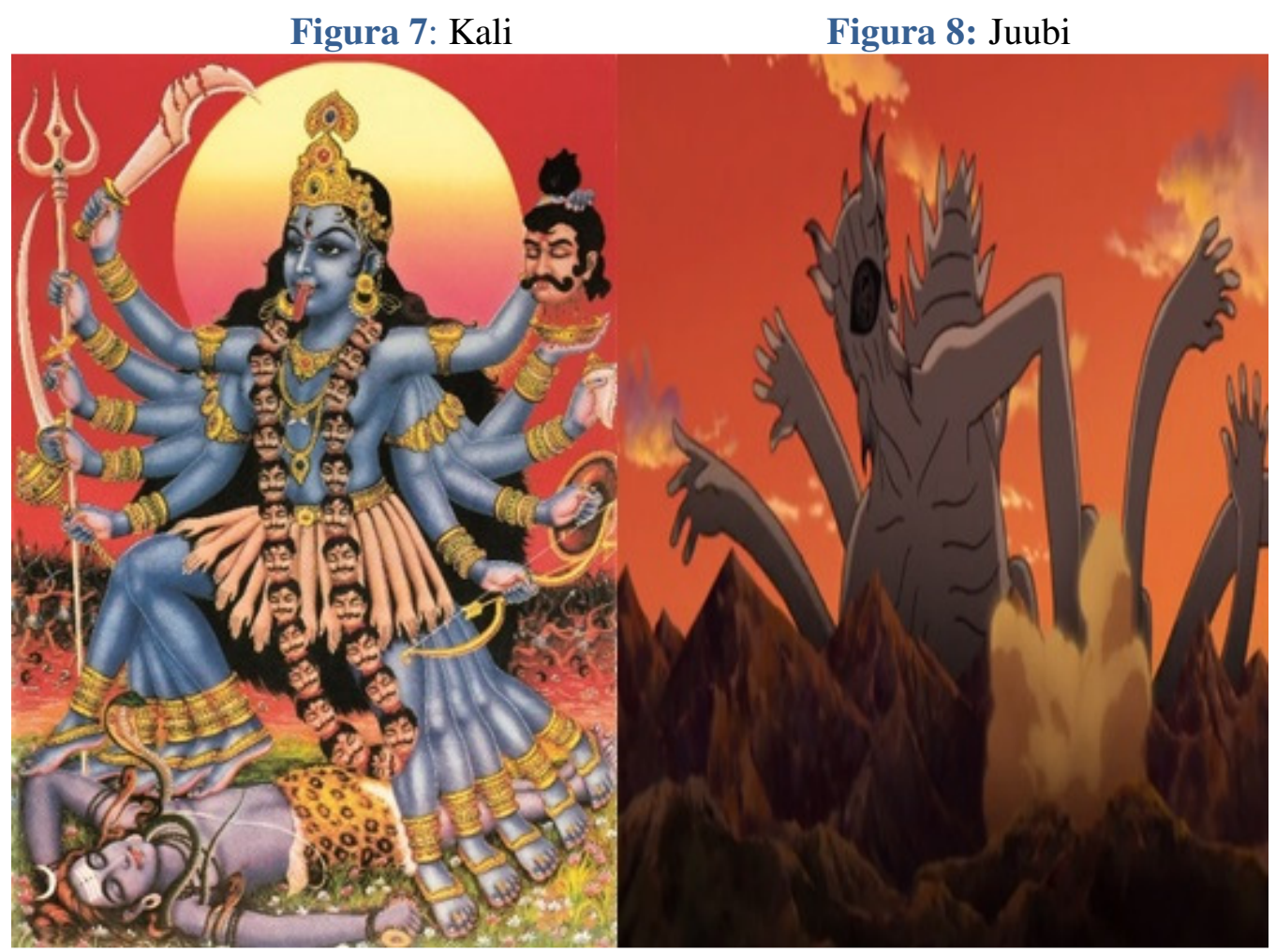

Fonte: Deusa Kali. Disponível em: https://www.kalicollective.com/blog/2018/5-waysto-invoke-the-energy-of-the-goddess-kali Acessado em 27/11/2019 e KISHIMOTO, Massami. Naruto Shippuden. Japão: Pierrot, 2007-2017 (23 minutos) 
No caso da figura 7, pode-se perceber os aspectos guerreiros de Kali carregados em suas dez mãos e logo aos seus pés está seu marido, imóvel devido sua dança constante. Ao relacionar com Kaguya, nota-se a presença da Árvore Divina ou Juubi (Figura 8) como o detentor de dez braços que enclausura em suas raízes as pessoas, sugando as suas energias, dentre eles está Tenji, seu marido. Kaguya, então, dança sob o corpo de Tenji e lança seus poderes ofensivos sob o mundo. Nos aspectos do anacronismo da imagem de Didi-Huberman (2011), verifica-se em ambas as figuras (7 e 8) uma relação de gestualidades, de tonalidades e de manifestações de memórias. Há em ambas o pôr do sol, o céu amarelado, a figura de uma entidade destrutiva e criadora com tonalidades mais escuras e detentora de inúmeros braços. Kali e a Árvore Divina (Juubi) emanam alegorias da destruição apresentadas pelo pôr do sol, ou seja, de um dia que se foi e que deve se preparar para o cair da noite.

Além dessas transtemporalidades de imagens mitológicas, é possível verificar a conexão com o mito romano que introduz a constelação de Gêmeos que também está relacionado a dualidade e se modela diante dos mitos de Castor e Pollux. Ambos são filhos de Leda e de Zeus, que estava disfarçado em cisne. Conforme narrado nas 'Argonáuticas' de Apolônio de Rodes (século IV a.e.c.), Castor era domador de cavalos e Pollux lutador (RODIO, 1919: p. 14). Eram inseparáveis e sempre buscavam se apoiar um no outro. Quando em batalha, na guerra com Idas e Linceus, Castor morre, o que deixa Pollux inconsolável. O irmão sobrevivente pede a Zeus que lhe permita oferecer a vida pela do irmão e o deus consente que eles vivam alternadamente, um dia na terra e outro no céu, sob a constelação de Gêmeos. Essa narrativa presente na ‘Argonáuticas' demonstra a relação de proximidade e cooperação dos irmãos, muito similar ao aspecto de harmonia existente entre Hagoromo e Hamura, em que o primeiro vive na Terra e o outro, na Lua.

Os filhos de Kaguya são imagens transtemporais desses aspectos dos irmãos mitológicos que se opõem e, ao mesmo tempo, se completam como é o caso da relação entre o céu e o submundo, o dia e a noite, a lua e o sol, o 
inverno e o verão. Kaguya concebe ambos e se demonstra como uma imagem transtemporal desse movimento entre ordenação e destruição que acompanhará as reencarnações dos irmãos em outros personagens, como é o caso de Naruto Uzumaki e Uchiha Sasuke, até que a deusa retorne e impere à condição de conflito novamente entre a humanidade e a reencarnação de seus filhos ou, no caso, dos filhos de Hagoromo.

\section{Considerações finais}

Kaguya, Hagoromo e Hamura são imagens que elencam entrelaçamentos temporais e mitológicos de mundos passados presentes nas mitologias antigas. É possível ver nas imagens destes personagens, os vestígios de suas temporalidades, por meio da alegoria histórica e da tensão do contexto em que a imagem é analisada, e os seus mundos passados. Suas características físicas e éticas são presentificações de passados emitidos por narrativas e imagens míticas que inauguram a sua ressignificação no século XXI, no qual a alegoria histórica permite uma desmontagem de seus elementos, para identificar em seus variados tempos a relação deles com a presença de passado em consonância com o presente.

Em Kaguya é possível verificar a sua posição enquanto deusa da destruição, presentificando toda uma tradição iconográfica de divindades femininas regidas sob esse epíteto, como a deusa Kali. Por outro lado, Hagoromo e Hamura tornam presente aspectos ligados ao mito dos dois irmãos, dinamizando as tensões espaço/temporais entre o passado e o presente da imagem. Tal tensão, foi denominada por Benjamin (1984) como aura, e que é o elemento de suspensão da imagem dialética.

Esses aspectos são muito comuns em narrativas míticas, principalmente no mito cosmogônico, mas, ao emergir no presente, como em 'Naruto Shippuden', ganha contornos próprios de seu contexto espacial e temporal. Nas imagens de Kaguya e de seus filhos, seja pelas relações de gestualidades, de palavras emanadas, de suas posturas ou comportamentos, observa-se como os 
diversos tempos se chocam, se esparramam, diferente daquele linear e cronológico. Pois, é o tempo da (e na) imagem, dotado de anacronismos, de saltos temporais transmitidos pelas imagens das personagens analisadas, por meio de presenças de passados, que conflui todos os tempos com os quais a história foi produzida.

\section{Referências}

BANSAL, S. P. Deuses e deusas hindus. Rio de Janeiro: Nova Era, 2008.

BENJAMIN, W. A origem do drama barroco alemão. São Paulo: Brasiliense, 1984.

BÍBLIA DE JERUSALÉM. São Paulo: Editora Paulus, 2004.

BUSTAMANTE, R. M. da C. Rômulo e Remo: escritos e ritos. História Revista, v. 6, n. 2, p.87-116, jul./dez., 2001.

CAMPBELL, J. As máscaras de Deus: mitologia oriental. São Paulo: Palas Athena, 1994.

CHEVALIER, J.; GHEERBRANT, A. Diccionario de los símbolos. Barcelona: Editorial Herder, 1986.

DAL PRA, M. Cabala. In: Enciclopedia Einaudi. Volume 18. Lisboa: Imprensa Nacional da Casa da Moeda, 1990.

DIDI-HUBERMAN, G. Diante do tempo: história da arte e anacronismo das imagens. Belo Horizonte: Editora UFMG, 2015.

DIDI-HUBERMAN, G. Ante el tiempo. Buenos Aires: Adriana Hidalgo, 2011.

ELIADE, M. Mito e Realidade. São Paulo: Editora Perspectiva, 1972.

ELIADE, M. O Sagrado e o Profano. São Paulo: Martins Fontes, 1992.

ELIADE, M. Tratado de História das Religiões. São Paulo: Martins Fontes, 2008.

GUMBRECHT, H. U. Produção de presença: o que o sentido não consegue transmitir. Rio de Janeiro: Contraponto, 2010.

KISHIMOTO, M. Naruto Shippuden. Japão: Pierrot, 2007-2017 (23 minutos) 
KISHIMOTO, M. NARUTO- [Shinden Jin no Sho] Dados oficiais do personagem LIVRO, NARUTO [Hiden: Jin no Sho] Kyarakutā Ofisharu DētaBOOK). O4 de novembro de 2014. 391 páginas. Disponível em: https://naruto.fandom.com/pt-br/wiki/Kaguya_\%C5\%8Ctsutsuki Acessado em: 21/11/2019.

NETO, G. F. S. Paixões e Traços Míticos no discurso do Animê: uma análise em Death Note. 2013. 125 f. Dissertação (Mestrado em Letras e Linguística). Universidade Federal de Goiás, Goiânia, 2013.

RODIO, A. La argonáutica. Tomo primeiro. Madrid: Biblioteca Nacional de España, 1919.

LÉVI-STRAUSS, C. Antropologia Estrutural. Rio de Janeiro: Tempo Brasileiro, 1975.

WARBURG, A. História de fantasmas para gente grande: escritos, esboços e conferências. São Paulo: Companhia das Letras, 2015.

Recebido em: 27 de janeiro de 2020 Aceito em: 30 de abril de 2020 